\author{
J. Jasiński, K. Mendzik, M. Tatar, M. Szota \\ Czestochowa University of Technology, Faculty of Materials Processing Technology \\ and Applied Physics, Institute of Materials Engineering Częstochowa, Poland
}

\title{
OXIDE COATINGS ON TITANIUM PRODUCED BY OXIDATION IN FLUIDIZED BED
}

\begin{abstract}
The main product of a process of titanium oxidation is titanium oxide, which covers the titanium surface. Moreover oxidation in fluidized bed in temperature range of $600-700^{\circ} \mathrm{C}$ influences on outer layers of titanium specimen, where a diffusion layer of oxygen is observed. Microstructures of titanium with visible oxide coatings on its surface after thermo-chemical treatment are described. Microhardness measurements of titanium surface layers after oxidation process were made with a Knoop microhardness tester and showed significant differences according to oxidation parameters. Finally, the surfaces of titanium after oxidation in fluidized bed were scratched in aim to measure their adhesion to the substrate surface.
\end{abstract}

Key-words: titanium, oxidation, fluidized bed, adhesion

\section{INTRODUCTION}

Biomedicine is intensively developing and use of titanium and its alloys in the field of reconstruction of damaged anatomical structures increases. A need of searching new, better biomaterials for implants [1] and medical tools is being realized for example by testing new titanium alloys [2,3]. But often a production of a new alloy is very expensive, so researchers trying to find a proper surface engineering method to improve properties of pure titanium or popular titanium alloys, such a Ti6Al4V $[4,5]$.

Implants are working in very aggressive environment, which is human body, and they should have good corrosion resistance and biocompatibility. An oxide coating produced in titanium oxidation can ensure these properties [6,7].

High oxygen affinity to titanium makes that this material is easy covered with oxide $\mathrm{TiO}_{2}$ coat (even at room temperature), which is stable and very adherent to the surface. The coating existing in room temperature is very thin and not provides enough surface protection. At high temperatures titanium oxidizes very fast, and it results in thicker, but often porous or cracked and not enough adherent to the surface oxide coating [8]. The trend is to combine advantages of high and low temperature oxidizing of titanium using for that reason various treatment methods. 
Effects of titanium oxidation depend mainly on process temperature, but the time of oxidation is also important. The dependency of oxidation parameters on oxide coating adhesion is shown in figure 1.

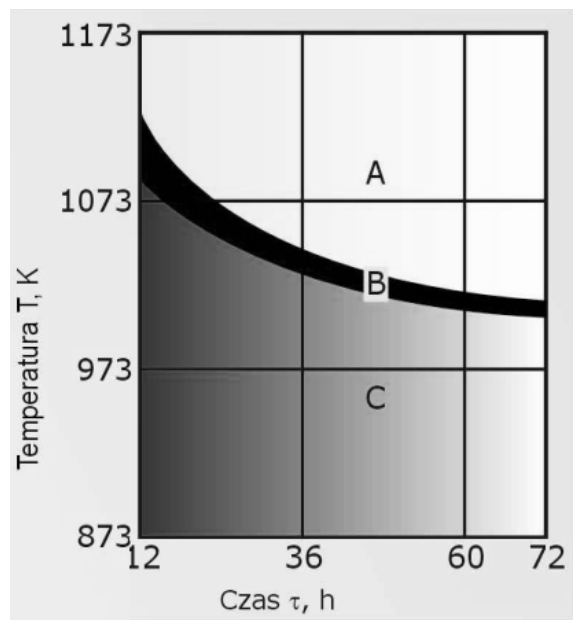

Fig. 1. The correlation between oxidation parameters and adhesion of oxide coating by Jenkins [5]

There are very little notifications about treatment in fluidized bed furnaces. In this paper examination results of produced oxide coatings and diffusion layers in process of titanium oxidation in fluidized bed are shown.

\section{EXPERIMENTAL PROCEDURE}

Test specimens were cut off from technical pure titanium (Ti grade 1 - ISO 5832-2, ASTM B 265-99) sheet thickness $2 \mathrm{~mm}$. Chemical composition of used titanium is shown in table 1.

Table 1. Chemical composition of titanium used in experiments

Chemical composition (\% weight)
\begin{tabular}{|c|c|c|c|c|c|}
\hline $\mathrm{Fe}$ & $\mathrm{C}$ & $\mathrm{N}$ & $\mathrm{O}$ & $\mathrm{H}$ & $\mathrm{Ti}$ \\
\hline 0,035 & 0,009 & 0,002 & 0,063 & 0,028 & Rest \\
\hline
\end{tabular}

Before oxidation titanium samples were polished using 1000 grit $\mathrm{SiC}$ abrasive paper, followed by degreasing with ethanol. The titanium oxidation process in fluidized bed was carried out in air atmosphere using parameters shown in table 2.

After oxidation process samples were polished and then were etched in reagent composed of: $2 \% \mathrm{HF}, 2 \% \mathrm{HNO}_{3}, 96 \% \mathrm{H}_{2} \mathrm{O}$.

Microstructure observations were performed in a light microscope Axiovert 25 combined with digital camera Sony Fd Mavica. 
Table 2. Titanium oxidation process parameters

\begin{tabular}{|c|c|c|c|}
\hline $\begin{array}{c}\text { Sample } \\
\text { no. }\end{array}$ & Temperature, $\mathrm{K}$ & Time, $\mathrm{h}$ & \multirow{2}{*}{ Atmosphere } \\
\hline 1 & 973 & 10 & \multirow{2}{*}{ Air } \\
\hline 2 & 923 & 5 & \\
\hline 3 & 923 & 15 & \\
\hline 4 & 873 & 10 & \\
\hline
\end{tabular}

The effects of oxidation on changes in microhardness of titanium diffusion layer were specified by the Knoop microhardness test using tester type FM-7 Future Tech Corp. The load amount was $98 \mathrm{mN}$, and load time was 6 seconds.

Adhesion measurements and other symptoms of mechanical damage were performed by a scratch test method on REVETEST machine (CSEM). The load increases from 0 to $100 \mathrm{~N}$ with a load speed $100 \mathrm{~N} / \mathrm{min}$. The test intender was a Rockwell C type, which moving speed was $10 \mathrm{~mm} / \mathrm{min}$.

\section{RESULTS AND DISCUSSION}

In aim to compare effects of oxidation process parameters there was photos of titanium microstructures taken. Metallographic observations allowed to find that oxide coatings produced by oxidation in fluidized bed in temperature range of 873-973 K can much differ in thickness (fig. 2).

a)

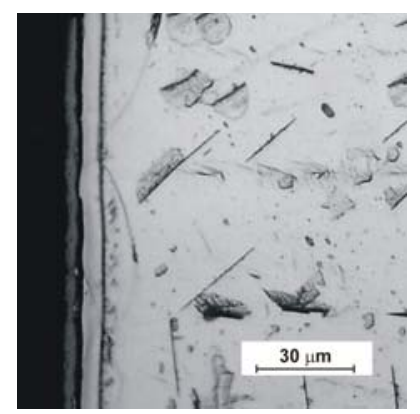

c)

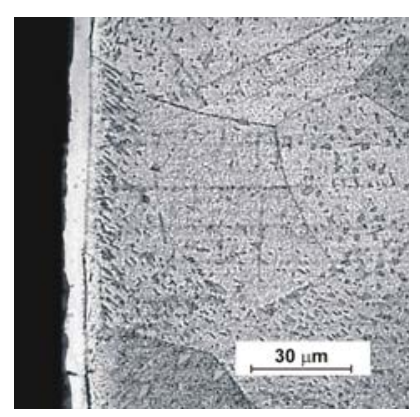

b)

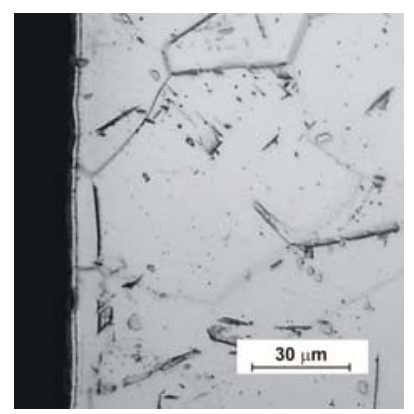

d)

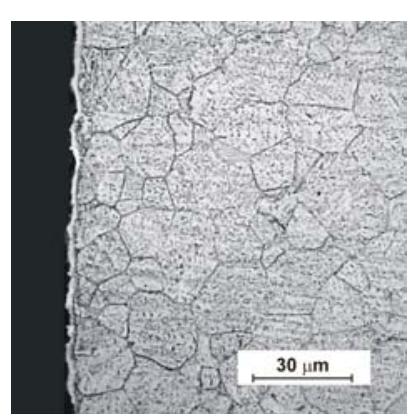

Fig. 2. Titanium microstructure after oxidation in fluidized bed; a) $973 \mathrm{~K}, 10 \mathrm{~h}$, b) $923 \mathrm{~K}, 5 \mathrm{~h}, \mathrm{c}) 923 \mathrm{~K}, 15$ $\mathrm{h}, \mathrm{d}) 873 \mathrm{~K}, 10 \mathrm{~h}$ 
In the same time of oxidation, coating obtained on titanium surface treated at $973 \mathrm{~K}$ is about 4 times thicker then this obtained at $873 \mathrm{~K}$. Effects of oxidation at temperature $923 \mathrm{~K}$ in 5 hours time are similar to effects after oxidation at temperature $873 \mathrm{~K}$, but in 5 hours longer time. Moreover thickness of coatings produced at $973 \mathrm{~K}, 10 \mathrm{~h}$ and at 923 $\mathrm{K}, 10 \mathrm{~h}$ are comparable too. Therefore can be stated that temperature and time of the process have great influence on coating growing speed.

Oxidation of titanium not only influences on the surface, but during this thermochemical treatment diffusion of oxygen into titanium is running too. Processes of diffusion causing a rise of strength under the coating, because of increased concentration of oxygen in titanium. How deep from the surface diffusion has its influence can be measured in microhardness test. The greatest strengthening is near the surface of oxidized titanium and decreases when the distance from coating-titanium interface is bigger.

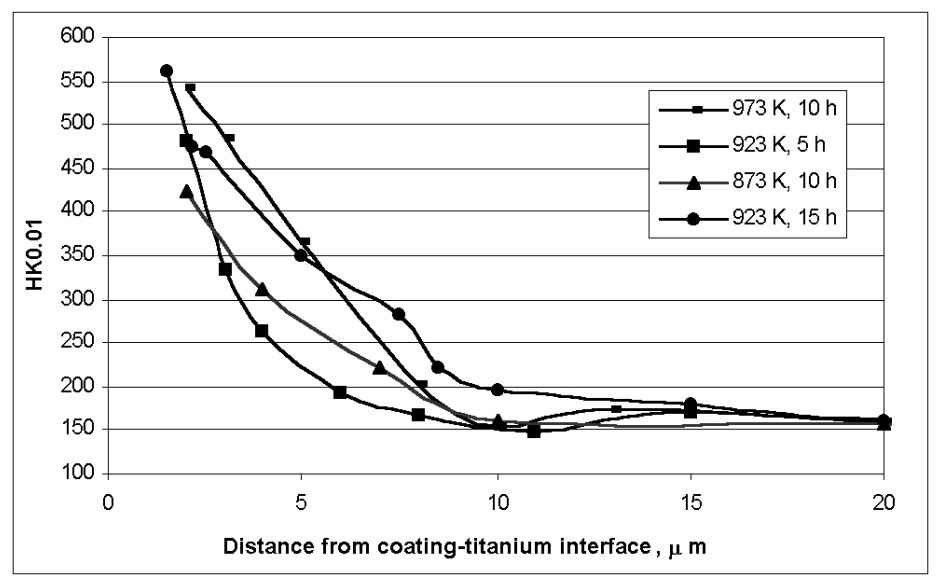

Fig. 3. Microhardness profiles of diffusion layers after titanium oxidation in fluidized bed

In figure 3 results of microhardness measurements are shown. The oxygen diffusion in used times is not very intensive process. Maximum determined depths of oxygen influence on titanium substrate is about $13 \div 14 \mu \mathrm{m}$ after oxidation in fluidized bed at $923 \mathrm{~K}$ for 15 hours. Oxidation in the shortest presented time caused that diffusion layer is only $7 \mu \mathrm{m}$ deep. Moreover 10 hours oxidation at temperature 873 and $973 \mathrm{~K}$ resulted in production of comparable diffusion layers thickness. In these process parameters increased concentration of oxygen was specified to about $10 \mu \mathrm{m}$ from the titanium surface. Very interesting is that the deepness of oxygen diffusion penetration into titanium, in used oxidation temperature range, depends mostly on time of the process and temperature is much less significant parameter in this field.

Determining of critical loads $\mathrm{L}_{\mathrm{c} 1}, \mathrm{~L}_{\mathrm{c} 2}$ and $\mathrm{L}_{\mathrm{c} 3}$ for $\mathrm{TiO}_{2}$ coating was possible only for titanium oxidized in temperature $973 \mathrm{~K}$ for 10 hours (fig. $4 \mathrm{a}$ ). On the rest of samples coatings are too thin and undergo a perforation from the beginning of the scratch test. 
a)
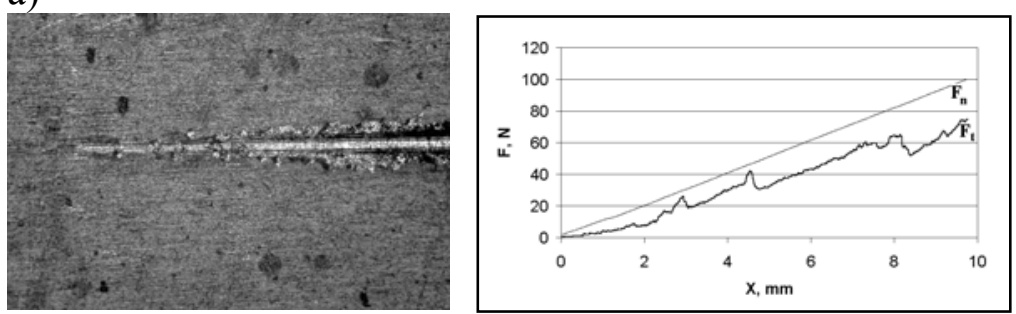

$4,19 \mathrm{~N}$ - first crack- $\mathrm{L}_{\mathrm{cl}}$

$6,09 \mathrm{~N}$ - first spall near the edge of scratch $-\mathrm{L}_{\mathrm{c} 2}$

$11,35 \mathrm{~N}$ - remove of the coating $\left(\mathrm{TiO}_{2}\right)-\mathrm{L}_{\mathrm{c} 3}$

$29,12 \mathrm{~N}$ - remove of next layer

b)
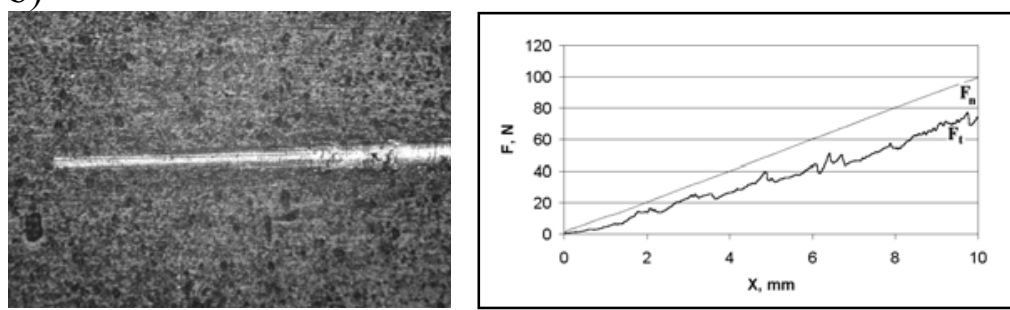

$0,82 \mathrm{~N}$ - perforation of coating

$4,19 \mathrm{~N}$ - first spall near the edge of scratch

$5,35 \mathrm{~N}-$ start of cracking

$17,55 \mathrm{~N}$ - complete remove of "gray" layer

c)
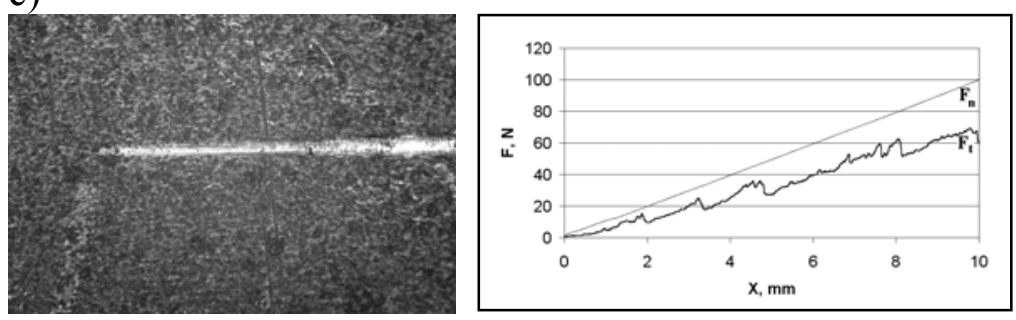

$4,60 \mathrm{~N}$ - first crack

$16,69 \mathrm{~N}$ - first spall near the edge of scratch

$67,60 \mathrm{~N}$ - complete remove of "gray" layer

d)
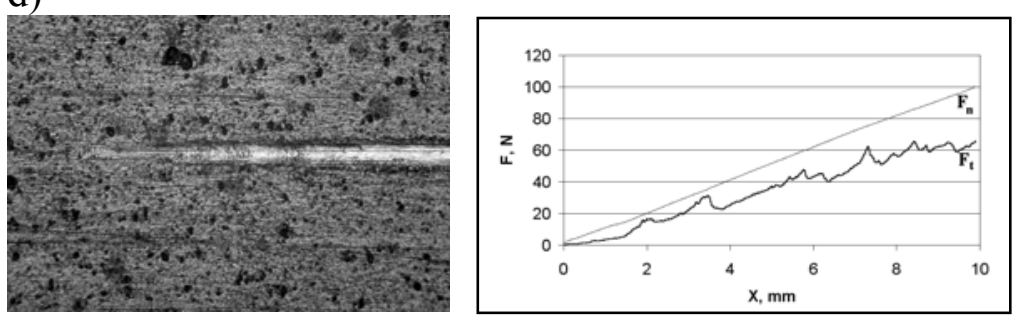

$1,34 \mathrm{~N}$ - first spall in the scratch

$2,70 \mathrm{~N}$ - first crack

$8,28 \mathrm{~N}$ - discontinuous perforation of "gray" layer

$20,06 \mathrm{~N}$ - complete remove of "gray" layer

Fig. 4. Pictures of scratches obtained in scratch test on oxidized titanium surfaces and plots of measured changes in forces during the test

Because of too big loads for such a thin coatings, and problems with determining critical loads for all specimens, it was suggested that the best for comparing coatings adhesion will be the force of first observed spall near the scratch. The best results were obtained for coating produced at $923 \mathrm{~K}$ after 15 hours of titanium oxidation. A "gray" layer can be described as diffusion layer of oxygen in titanium. Load values are related to thickness of these layers. The thicker is diffusion layer the bigger load was needed for complete remove of it.

\section{CONCLUSIONS}

Thickness of $\mathrm{TiO}_{2}$ coating can be controled by temperature and time of titanium oxidation

Time of oxidation process in fluidized bed is being major factor for diffusion layer thickness at used parameters. 
Probably the best adhesion characterized oxide coating produced on titanium at 923 $\mathrm{K}$ during 15 hours of process time

\section{ACKNOWLEDGMENT}

This work was financially supported from science sources for years 2005-2007 (research project - no. 3 T08C 05129 )

\section{REFERENCES}

1. R. Langer: Biomaterials and biomedical engineering. Chemical Engineering Science 50, 1995, pp. 4109-4121.

2. M. Niinomi, D. Kuroda, K. Fukunaga, M. Morinaga, Y. Kato, T. Yashiro, A. Suzuki: Corrosion wear fracture of new $\beta$ type biomedical titanium alloys. Materials Science and Engineering A263, 1999, pp. 193-199.

3. Y. Okazaki: A new Ti-15Zr-4Nb-4Ta alloy for medical applications. Current Opinion in Solid State and Materials Science 5, 2001, pp. 45-53.

4. X. Liu, P.K. Chu, C. Ding: Surface modification of titanium, titanium alloys, and related materials for biomedical applications. Materials Science and Engineering R 47, 2004, pp. 49-121.

5. F.H. Jones: Teeth and bones: applications of surface science to dental materials and related biomaterials. Surface Science Reports 42, 2001, pp. 75-205.

6. P.F. Chauvy, C. Madore, D. Landolt: Variable length scale analysis of surface topography: characterization of titanium surfaces for biomedical applications. Surface and Coatings Technology 110, 1998, pp. 48-56.

7. M.C. Garcia-Alonso, L. Saldaña, G. Valles, J.L. Gonzalez-Carrasco, J. GonzalezCabrero, M.E. Martinez, E. Gil-Garay, L. Munuera: In vitro corrosion behaviour and osteoblast response of thermally oxidised Ti6Al4V alloy, Biomaterials, 2003, pp. 19-26.

8. S. Król: Mechanizm i kinetyka utleniania tytanu oraz wybranych stopów tytanu. Studia i Monografie WSI-Opole 82, 1994. 